\title{
Engineering Innovators without Borders: Developing Entrepreneurial Opportunities for the Developing World through Engineering Redesign
}

\author{
Kevin McGarvey, Grad Student \\ Civil Engineering \\ Rowan University \\ Glassboro, NJ 08028 \\ Mcgarv32@students.rowan.edu \\ Michael Panko, Senior \\ Mechanical Engineering \\ Rowan University \\ Glassboro, NJ 08028 \\ Pankom41@students.rowan.edu
}

\author{
Michael Biggs, Senior \\ Mechanical Engineering \\ Rowan University \\ Glassboro, NJ 08028 \\ Biggsm42@students.rowan.edu \\ Nicole Bacher, Junior \\ Civil Engineering \\ Rowan University \\ Glassboro, NJ 08028 \\ Bacher60@students.rowan.edu
}

\author{
Jesse Hill, Senior \\ Mechanical Engineering \\ Rowan University \\ Glassboro, NJ 08028 \\ Hilli20@students.rowan.edu \\ Beena Sukumaran, \\ Associate Professor \\ Civil and Environmental \\ Engineering \\ Rowan University \\ Glassboro, NJ 08028 \\ sukumaran@,rowan.edu
}

Abstract - "Engineering Innovators without Borders" seeks to establish entrepreneurship opportunities for the developing world. Through the Junior/Senior engineering clinics at Rowan University, engineering and business majors work together to develop sustainable devices and business plans. The first technology developed by this project is the human powered grain crusher. The grain crusher project aims to create a cheap and simple mechanical device to grind barley, corn, and other grain. The grain crusher utilizes human energy to crush grains quickly and efficiently. The goal is to provide technological solutions to problems in the developing world by using detailed opportunity recognition evaluations and development of prototypes. The prototypes are then turned over to the developing world for manufacture, distribution, and use. The projects are expected to provide entrepreneurial opportunities for the developing world, alleviate poverty, and improve the quality of life. The grain crusher will be adopted by the DHAN Foundation in India for manufacturing and piloting.

Index Terms - clinics, entrepreneurial, prototypes, sustainable

\section{INTRODUCTION}

"Engineering Innovators without Borders" has been a project at Rowan University since Fall of 2006. It was started in order to provide entrepreneurial opportunities to the Developing world. The Development of Humane Action (DHAN) foundation ${ }^{1}$ is a professional organization with the objective of bringing highly motivated and educated young women and men to work on bringing out new innovations in rural development and for up scaling development interventions to eradicate poverty in vast areas of India. The idea is by inventing, and through the DHAN foundation, distributing a device that provides a needed service to people in these countries, businesses can develop in Indian villages and make the villages self-sustaining. If it works well in India, the scope of the project can be expanded to other developing world countries. The first project is a human powered grain crusher that is lightweight, relatively inexpensive to make, and 
much faster than the mortar and pestle method currently used for grinding grain in most of the developing world. There are two finished designs, one of which is a standalone device; the other needs to dock with a bicycle in order to grind grains. The two grain crushers were brought for a pilot study outside of Madurai, India. The crushers were designed to be reproduced using readily available local materials. The pilot study took place from December 26, 2008 to January 4, 2009. The villagers gave us suggestions on improving the device from a user's perspective. The grain crusher has currently been improved incorporating the suggested design changes of the villagers. There are several other projects that "Engineering Innovators without Borders" is looking into developing. A peanut shell remover, a coconut tree climber, a soil tiller, and a paddy harvester are currently options for the next device to be developed.

\section{BACKGROUND}

\section{Engineering Clinics at Rowan University}

Rowan University is a strong proponent of experiential learning, a "bottom-up" method in which general lessons and principles are learned through direct personal experiences and observations. Active modes of learning can enrich, broaden and deepen the knowledge base, which is gained from readings and class lectures ${ }^{2,3,4}$. It will be demonstrated in the following sections that experiential learning is a hallmark of Rowan's engineering and business curriculum, which will both be utilized for this project. This project was introduced in the Fall of 2006 through the Engineering Clinic program at Rowan University. This is an eight semester project based learning course that is a requirement of all engineering students for graduation. Professionalism and "Real-Life" engineering practices are emphasized in a multidisciplinary environment. The layout of the Engineering Clinic program can be seen in Table I. Freshman Clinic is a twosemester long course that introduces freshman to engineering at Rowan University. In Freshman Clinic, the students are introduced to a hands-on, active learning environment through a 3-hour weekly lab and a 1-hour weekly class meeting schedule. The first semester of the course focuses on multidisciplinary engineering experiments using engineering measurements as a common thread. The second semester focuses on the reverse engineering of a commercial product or process. Sophomore Clinic I combines a 1-credit multidisciplinary engineering laboratory with a 3-credit college composition and rhetoric requirement and is co-taught by engineering and composition and rhetoric faculty. The 3-hour laboratory for the course is a semester-long multidisciplinary design project, with an emphasis on parametric design. Sophomore Clinic II follows the same structure as Sophomore Clinic I, with public speaking as the 3 credits of required technical communications ${ }^{5,6,7}$. Students enrolled in the Junior/Senior Engineering Clinic work in teams to carry out independent research projects. The Junior/Senior Engineering Clinic, a 4-semester required course, is an integral part of the engineering curriculum in which students apply engineering principles to emerging technologies. Students work on service related projects or research grants funded by industry or government in multidisciplinary teams. The makeup of the teams is driven by the requirements of the project. Teams of students will be organized based on their particular skills, interests and background, and matched to a particular project. The service related projects offered through the junior and senior clinics are not meant to be a volunteer extracurricular activity ${ }^{3}$. The projects usually have regional, national or international impact. "Engineering Innovators without Borders" was introduced through Junior/Senior Engineering Clinics ${ }^{1}$. 
TABLE I

Overview of general technical topics in the eight-semester Engineering Clinic sequence

\begin{tabular}{|c|c|c|}
\hline Year & Engineering Clinic Theme (Fall) & Engineering Clinic Theme (Spring) \\
\hline $\begin{array}{l}\text { First Year } \\
\text { Sophomore }\end{array}$ & $\begin{array}{l}\text { Engineering Measurements } \\
\text { Multidisciplinary Design Modules }\end{array}$ & $\begin{array}{l}\text { Competitive Assessment Laboratory } \\
\text { 16-Week Multidisciplinary Design } \\
\text { Project }\end{array}$ \\
\hline $\begin{array}{l}\text { Junior } \\
\text { Senior }\end{array}$ & $\begin{array}{l}\text { Product Development } \\
\text { Multidisciplinary Capstone } \\
\text { Design/Research Project }\end{array}$ & $\begin{array}{l}\text { Process Development } \\
\text { Multidisciplinary Capstone } \\
\text { Design/Research Project }\end{array}$ \\
\hline
\end{tabular}

\section{Motivation}

In order to find an appropriate technology that could be used in the developing world, the needs of the people there had to be studied. Other considerations included local availability of materials, power and electricity usage and reliability, cost, ergonomics, and local impact. Based on suggestions by the faculty at Rowan University, which were based on a survey conducted through Engineers without Borders in Senegal, a device that crushes grain more efficiently than mortar and pestle was decided upon.

In researching available human powered grinding devices, it became evident that many people had attempted to create devices but most had focused on using relatively costly materials that are readily available in the United States but are most likely of limited supply in developing countries $^{8}$. The use of a bike to power a grinding device has been done by adapting exercise bikes to fit commercially available grinders but the price of the commercial grinders often exceeds the lifetime income of the target users of the device. The target group does not benefit from the creation of a device that exceeds their financial capabilities and so designs such as this should be reevaluated to determine their potential benefit.

In the last century, the industrialized world has revolutionized the grinding of grains through the use of metals making it a much less laborious and a more efficient process. The adaptation of this now fairly basic food production technology to countries where grain production is associated with long hours of back breaking labor would have great social and economic impact. People that now slave away for hours just to make enough flour for their own households could, with a modern grinding device, potentially produce enough flour for multiple families in an equivalent amount of time while exerting much less energy. The goals of the project are rooted in developing a device which is not overly complex and could be made from readily available materials so that the finished product of the project could become available to those in most need of it.

\section{Design}

To design the grain crusher, a design process was developed. There were several main qualifications that each design had to meet. Each design needs to be affordable, made from local materials, efficient and simple to use, and durable. Once one or more designs have met these qualifications, the pilot study will be conducted and based on that, one design will be chosen and refined for production. The design process has been laid out in a flow chart in Figure I. 


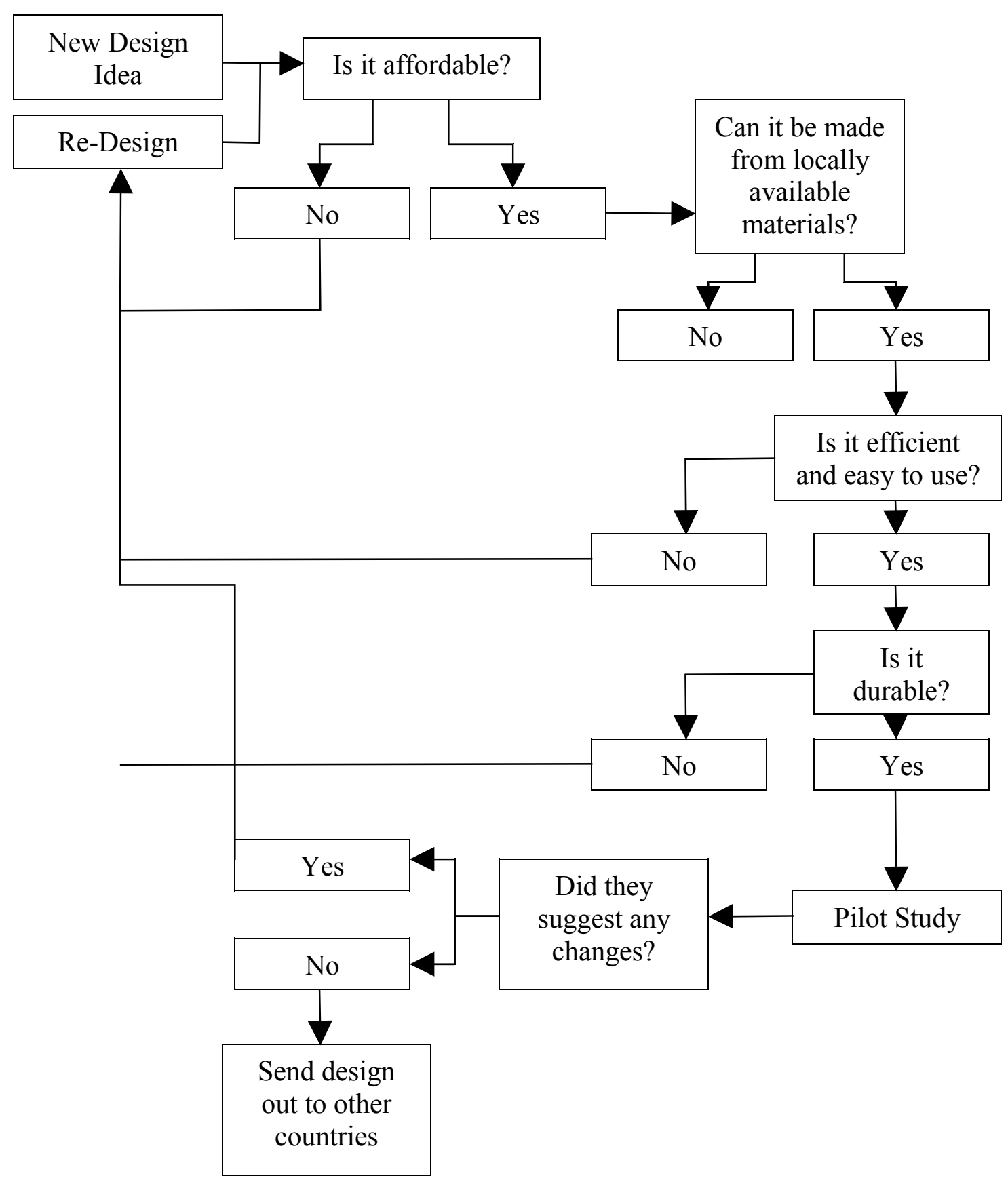

Figure I: Design Theory 
The original design concept was for a rotary stone grinder called a quern. It was decided that the most reasonable device to fulfill the purposes of this project would be the quern which is essentially two circular stones, one on top of the other, with an axle in the center and a handle attached to the top stone. The grain to be ground is placed between the two stones and the top stone is rotated about the axle. On more advanced designs, a small hole in the top stone allows for the continual introduction of fresh grain into the space between the stones. It is very efficient, effective, and constructed of all natural materials, which require very little machining. The quern and its direct descendent, the millstone, were so effective that they were the primary means for all grain production until the late 1800's. Some small scale modern mills, in fact, still operate using high quality, electrically-turned millstones that produce flour which is said to have better baking qualities than commercially available flour which is produced using metal grinding devices. Having chosen a design, using circular cement "paver" stones and a steel rod as an axle, a working quern was assembled and tested. It was tested by grinding various types of grains and proved to be adequate as a working model. Then the group started to contemplate what improvements could be made to a device that had existed in various forms for thousands of years. It was at this time that the realization was made that the quern had very little development potential, while keeping the cost at a reasonable level.

Having realized that making a quern would not allow any improvements beyond what already existed, the focus of the project shifted to a grinder that is produced in Uganda. The Ewing III grinder is produced in a manufacturing plant in Uganda that was set up by Compatible Technology International $(\mathrm{CTI})^{9}$, an organization that helps to improve food processing operations throughout Africa. Discovering the Ewing III grinder allowed us to shift our focus from designing a complete grinder to developing improved methods to power an existing grinder. We attempted to contact CTI in an attempt to acquire a Ewing III but never received a response. As an alternative, we selected the Country Living Grain Mill as a comparable substitute to the Ewing III grinder. The Ewing III grinder (left) is compared to the Country Living Grain Mill (right) in Figure II. Both of these grinders feature a top feed system. The grain is then gravity fed into an auger. The grain is then pushed into plates that grind the grain through a shearing motion. The outer plate turns when the user turns the crank, while the inner plate is motionless. The Ewing III grinder has been used both in the U.S. and in developing countries. The Country Living Grain Mill is mainly used for household applications. The main advantage of the Country Living Grain Mill is that the crank has a pulley on it so it can be belt driven as well without major modifications. 


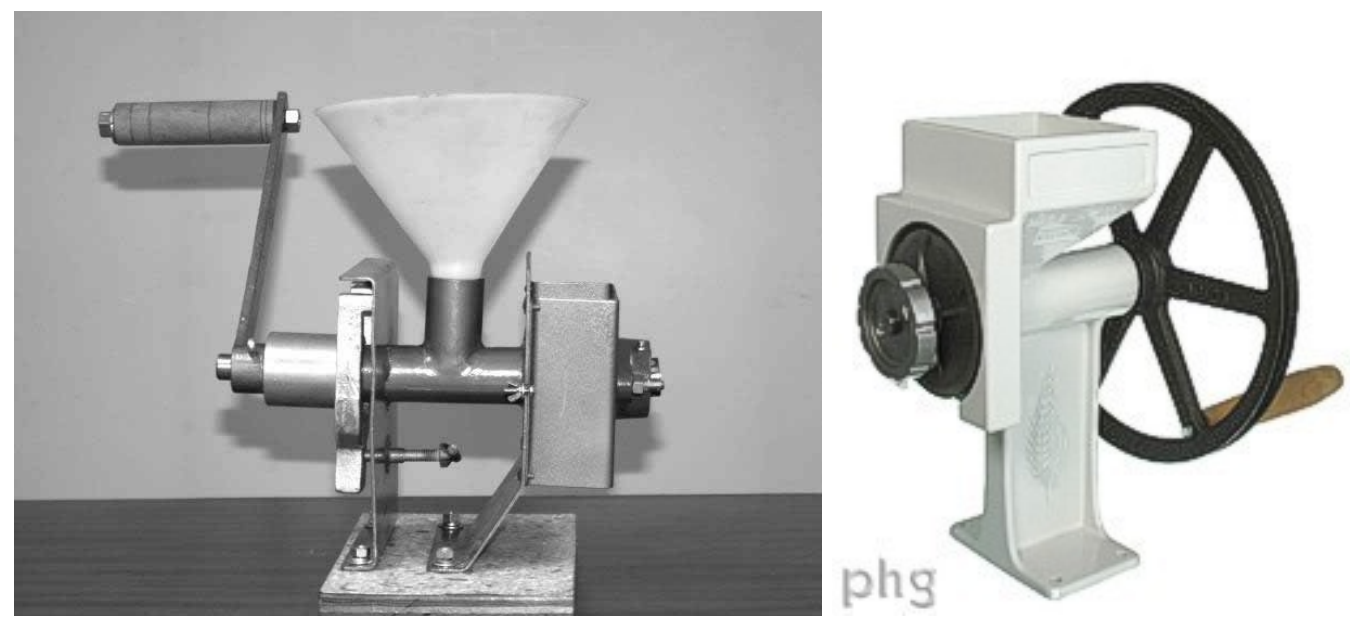

Figure II: Ewing III Grinder vs. Country Living grain Mill

In the Spring of 2007, the goal was making the grain crusher a device that could be produced at Rowan. For powering a grain crusher, a device is needed to convert human power to mechanical power for the grinder. Designs brainstormed and researched included bicycles or stationary bicycles modified with a chain or drive belt used to turn a crank on a personal, kitchen type grinder. The group decided that a bicycle stand for existing bicycle would be the best idea for the scope of the project. A bicycle stand was constructed with intentions to be attached to a pre existing grinder.

Of critical importance to the design was a wide range of adjustability so that the final product could fit a variety of bicycles. The stand would need to fit bikes with tire diameters ranging from 20 inches to 26 inches, and also with varying rear axle widths. The design also had to allow for adjustment to the tension in the drive belt, so it was decided that the grain crusher's location would be adjustable to provide such tension. The only fixed components would be the center drive axle and its supports. An overview of the previous design is shown below in Figure III. Everything but the bolts and bearings is made of 6061 aluminum, because this is just a prototype. The rear bike wheel is held in place by two "pucks" with holes lathed into them so that it fits over the nut on the back axle. The support shafts that hold that puck are adjustable in height. The wheel rests on a roller once it is properly secured. The roller has 80 grit grip tape on it to ensure more friction. When the bike is pedaled, the roller turns a 3 inch v-belt pulley which is belted to a 12 inch pulley on the grain crusher itself. Slots are milled into the base so that the belt can be tensioned or replaced. An effort was also made to use as many off-the-shelf pieces as possible. This would limit machining time and product variability for the end-user. It was also proposed to include an electric motor that could be powered by solar energy. This would give users the option of human or electric power, so if they do not have electricity, they are still able to use the device. 

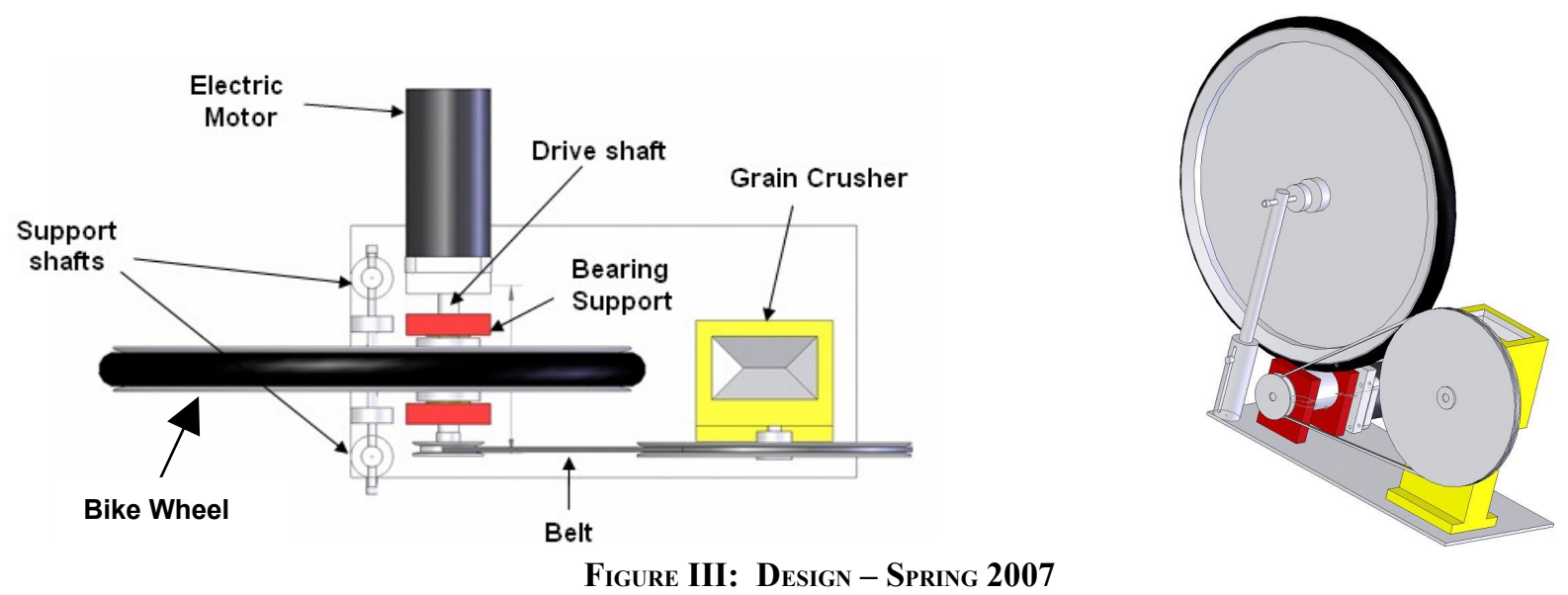

During the Fall 2007 semester, the objective of this project returned to the original objective with a focus on reducing cost and weight of the product. In order to accomplish this, the Spring 07 design was turned into a working model and analyzed to determine how best to reduce the cost. It was found that if the team could create its own grain crusher instead of ordering a readymade grinder. This change also reduced the weight of the product because the crusher was made from aluminum instead of much heavier cast iron. The new crusher is designed to retro fit onto the previous base. One of the main sources of cost and weight is the electric motor. Although it is a great benefit to use solar power and electricity to grind the grain, it was later determined that the device is easy enough to use that an electric motor would not be necessary. It is the same width and roughly the same height. The method of grinding remains the same. The grain is fed in through the top of the grinder and is augured through a hole. That hole allows the grain to fall between two grinding plates. One plate is bolted down, and other rotates and the shear force is what grinds the grain. The grinding plates are shown in Figure IV. An exploded view of the crusher is shown in Figure V, and the whole assembly is show in Figure VI (bicycle excluded).

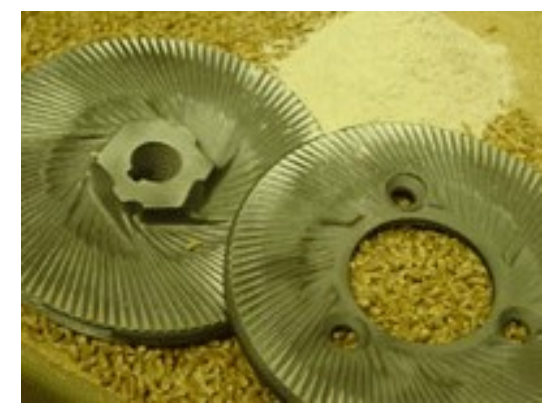

Figure IV: Grinding Plates Used fOR All Designs 


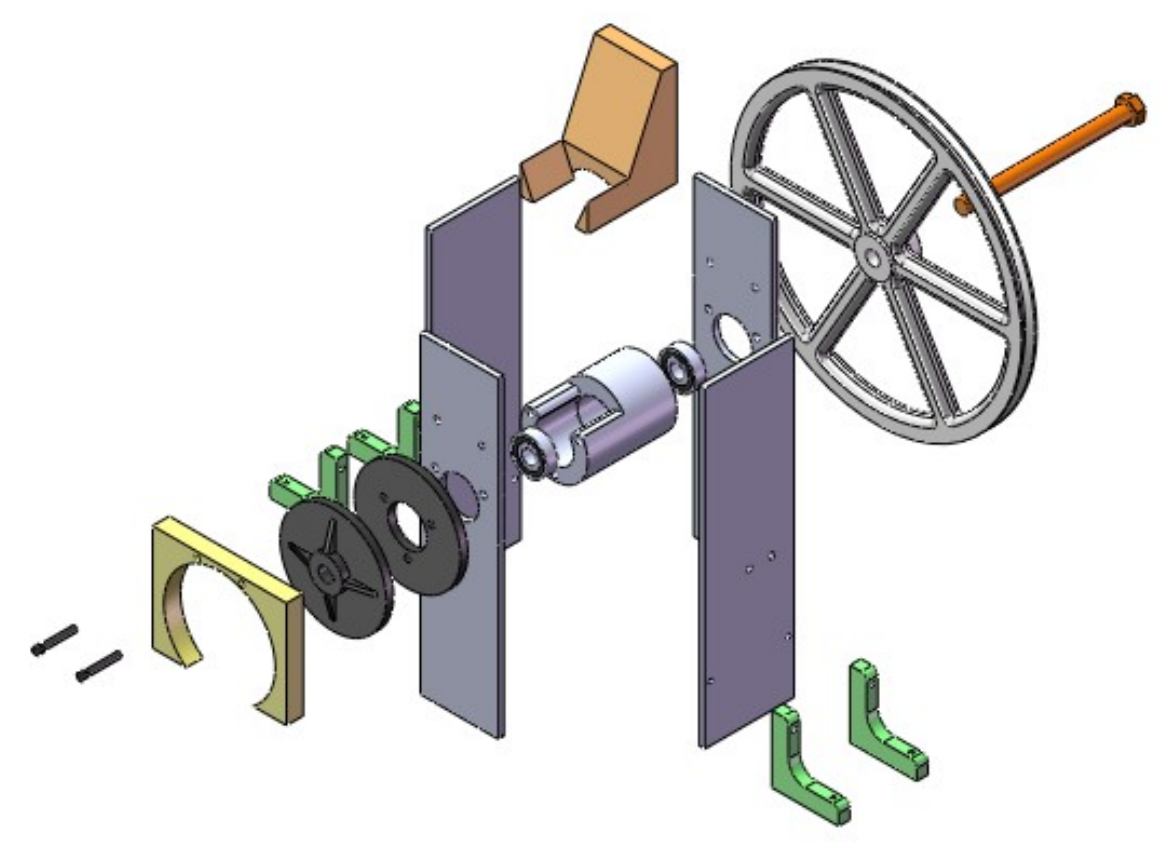

Figure V: Exploded View of Fall 2007 Design

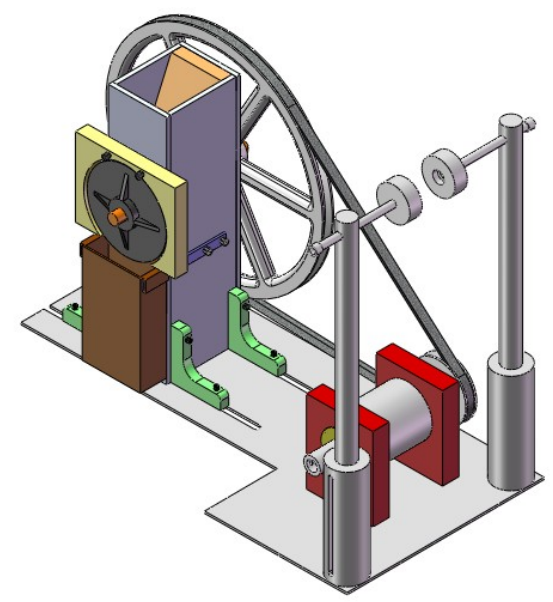

Figure VI: Solid Works Model of Fall 2007 DESIGN

Keeping the same idea of the prototype in mind, the total price of materials was a large difficulty. The pricing goes hand in hand with the conservation of materials, so when the excess material is trimmed down, the total cost of the product will have the same effect. The Spring '07 
design had a motor (\$225), Grain Crusher (\$375), and construction materials (\$200), so the cost of this design was approximately $\$ 800$ to build. For the Fall '07 design, the cost of the materials to make the crusher itself is approximately $\$ 224$, which shows that the objective of this project was reached. The new design costs $\$ 151$ less than the old one, excluding the motor. The motor was also eliminated from the design, saving more on the cost of the project. This would be one of the designs taken to India for the pilot study. These costs are based on cost of materials in the US and can be obtained much cheaper in the developing world.

This design was tested for how long it would take to grind different types of grain and roughly how much energy was required to grind each type of grain. A simple test was done by tying weights to a string and then tying the string to the shaft of the crusher. The maximum weight that could be lifted at a replicable rotational speed of about $1888 \mathrm{RPM}$ was $44.85 \mathrm{~N}$. The following formula was used to find the torque at the shaft of the grinder:

$$
T=r \times F
$$

Once the torque was known, we could find the power at the shaft:

$$
P=T \cdot \omega * 2 \pi
$$

Where $T$ is torque in $\mathrm{N}^{*} \mathrm{~m}$ and $\omega$ is the rotational speed in revolutions per second. The time required to grind one cup of each type of grain was recorded and the energy was calculated using:

$$
E=P * t
$$

Where $P$ is power and $t$ is time. The results of these tests can be found in Table II.

TABLE II

Time and Energy Required to Grind 1 Cup of Different Grains

\begin{tabular}{lrrrr}
\hline & $\begin{array}{l}\text { Split } \\
\text { peas }\end{array}$ & Rice & Popcorn & Barley \\
& & & \\
\hline Time to Crush Grain (s): & 111.34 & 37.02 & 158.28 & 39.94 \\
Energy Required (MJ): & 106.666 & 35.466 & 151.636 & 38.263 \\
\hline
\end{tabular}

The time required to grind one cup of grain is much faster than that of a mortar and pestle, which when tested took over 30 minutes to pound the grains listed as fine as the crusher, and the popcorn was nearly impossible. Although it is hard to calculate the energy required to use the mortar and pestle, a break was required between tests. Conversely, a break was not needed between each test on the grain crusher.

Since a replicable design was available, the Rowan University Business Department showed interested in working with the project. After meeting with the group of business students to show them our drawings and explaining the concept of the project they decided to work on the marketing side of the project. At present, the business team is doing research on areas the finished project can be marketed in. They are also presenting to a group of possible entrepreneurs that might be interested in becoming involved in the project.

Another goal that was established was to provide visibility for the product being designed. To do this, a website was assembled to showcase the Grain Crusher project. It gives a brief background of the project as well as our current status ${ }^{10}$. It also gives links to the types of products used to create the grain crusher device. The site is currently up and running and has been updated recently with a photo gallery and video clip of the working model. 
In the beginning of the Fall 2008 semester, it was decided that the grain crusher assembly should be made to be more reliable and user-friendly. The idea behind redesigning is that the current design may not be acceptable to all bicycles, such as mountain bikes or bikes with pegs. Also, it was decided that the grain crusher could be made cheaper and lighter, but still be sturdy by using steel. The new design still uses pedal power to turn the crusher, but it is self contained so that you will not need to attach a bicycle. To save money, the new design is made primarily out of steel. Steel is less expensive than aluminum, but it is stronger so fewer support components will be needed. It is also chain driven instead of belt driven.

Another great benefit of this design is it not only reduced the cost of the crusher to $\$ 250$, the weight also dropped from about $40 \mathrm{lbs}$ to $32 \mathrm{lbs}$. The design has the same grinder plates and loading system as the Fall 2007 design, except an auger was added to increase the feed rate of the grain that is being ground up. The seat has 6 adjustable height levels to make useable to a wide variety of people. The gear ratio is slightly greater than $1: 1$, but is still relatively easy to pedal. Energy calculations still have to be done on this design, but from observation the speed is slower, but it is easier to pedal than the Fall 2007 design. This design does have a slight learning curve when it comes to finding the correct height and getting used to pedaling while sitting directly above the axis of pedal rotation. The cross member that runs perpendicular to the chain direction is bent 5 degrees on both ends to reduce the "rock" effect and provides greater stability.

Figure VII shows the Fall 2008 design, without the funnel that is used to load the grain.

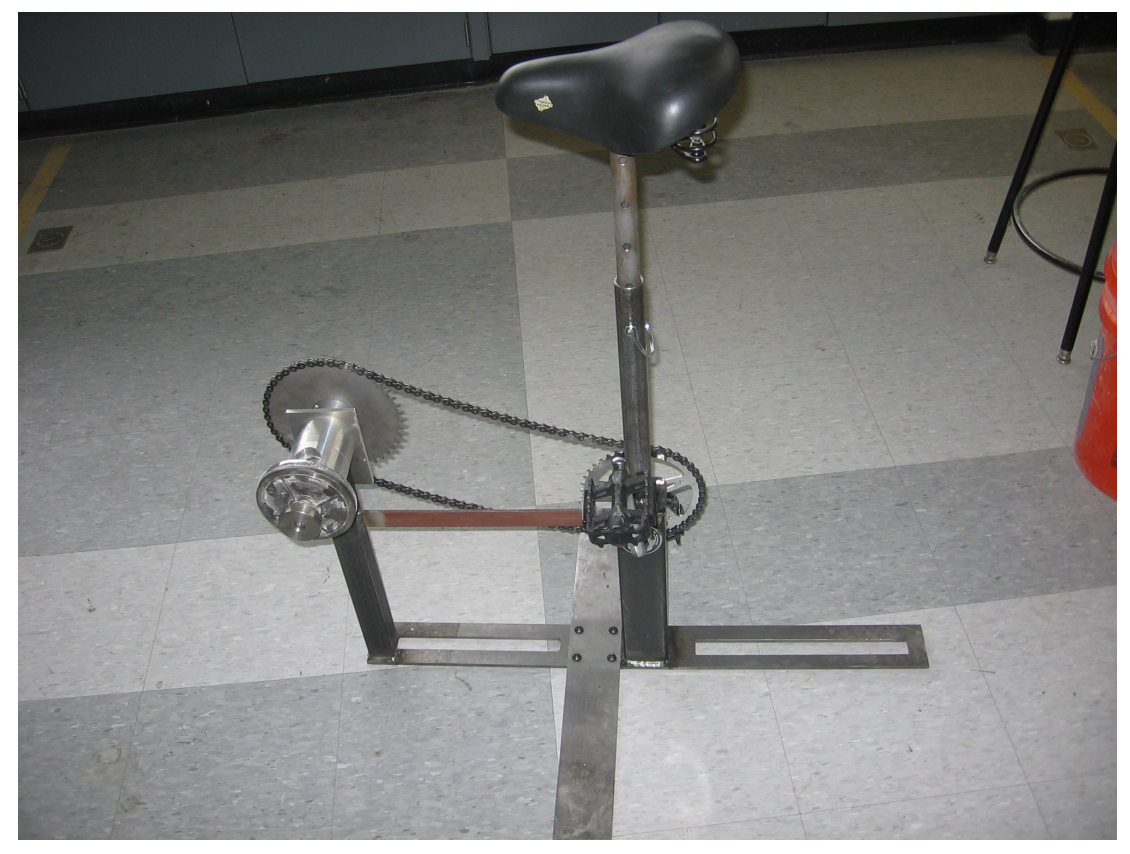

Figure VII: Fall 2008 Design

\section{Pilot Study}

With two designs completed, Fall 2007 and Fall 2008, preparation began for the pilot study. In order to save money, each design was brought as luggage on the flight. The one end of the base 
had to be trimmed an inch and a half in order to fit the airline's luggage size regulation. This did not affect the balance or the performance of the crusher.

Sengalpaddai was the village in which the pilot study was conducted. The first part of the pilot study involved investigating the current methods used to grind grain. One aspect that was not known was that they use a quern to "deshusk" lentils. Dehusking is the process in which the outer skin is removed and the lentil itself is broken in half. Once they separate the skin from the grain, they grind it up using a long stick and a bowl, a dry mortar and pestle, or a wet mortar and pestle (for flour).

The next step of the pilot study was to demonstrate how to use the Fall 2008 design. Once it was assembled, and a short demonstration was given, they took turns using the crusher. Once the villagers had done that, we repeated the process for the Fall 2007 design. An effort was made to let men, women, and children try the device and give feedback.

There were several major aspects that were observed. The first is that when adjusted properly, the crusher also removed the skin of the lentils very well. Also, not many of them wanted to sit on the seat and pedal, especially the women, because they did not want their clothes being caught up in the chain. Instead, they sat down behind the crusher and pedaled by hand. Another noteworthy observation is that the Fall 2007 may be a little faster, but it is difficult to collect the crushed grain. Overall, the newer design was much better received than the older design.

Once the trial was done, a roundtable discussion was held to receive feedback and suggestions to improve the design. The suggestions including larger grinding plates to improve capacity and a faster spin rate to increase capacity. Another suggestion was to make one hand powered handle, instead of the foot pedals. They also wanted a better collection system.

The objective of the Spring 2009 semester was to make final improvements on the design and distribute the crusher where it is needed. Based on the suggestions of the villagers, changes to the design were made. Allowing the grain crusher to be powered by either the arms or the legs is the major revision in the design. The new design was made to make this change simple and quick. In this design, the user can attach the pedals and adjust the bike seat to the right height, allowing them to use their legs. If the user prefers arm power, they could attach the handles to the pedal arms and remove the bike seat. This would also allow them to mount the crusher to a table, or sit down behind the crusher. The new design with the handles is shown in Figure VIII. Price is still a parameter, but since only the design drawings will be sent to India, size and weight is not as large of a concern. This is also only a guideline design for how to make a human powered grain crusher. The design can be changed to fit locally available materials. One example of this is the larger grinding plates. Madurai Mill Stores ${ }^{11}$ sells much larger grinding plates, and these are the plates that are available in the section of India in which the pilot study was conducted. The design of the hopper and feed line should be changed appropriately. Another aspect that should be taken into consideration is the gearing of the driveline. Any diameter ANSI 40 1/8 inch thick sprocket can be used, so the gearing can be adjusted to either be faster or be easier on the user. 


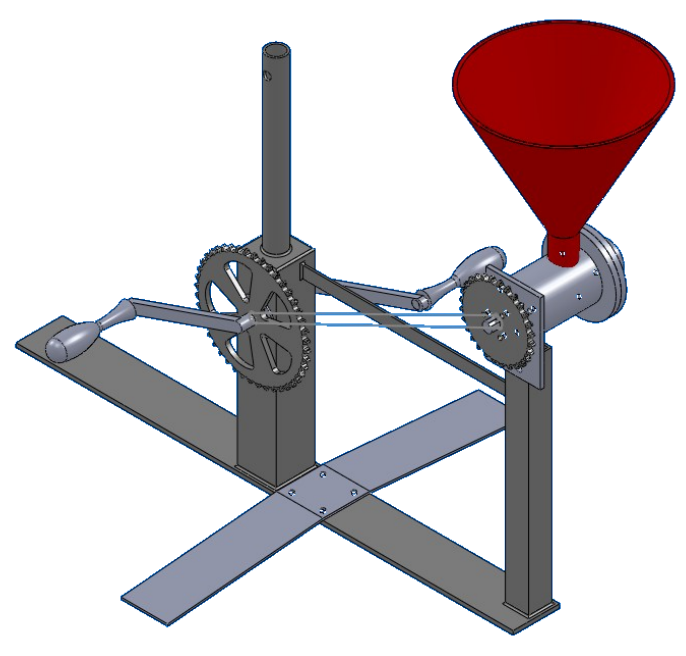

Figure VIII: Spring 2009 Design

\section{Future Work}

Now that the new design is completed, and a prototype built, performance calculations will be done. The energy calculations for the new design will make sure it still is relatively easy to grind the grain. Now that it is known what the villagers want in the design, the newest design should be the most ideal. If the prototype works well, the drawings will be sent the DHAN foundation where they will distribute the device to villages that need it in the effort to make them self sustaining.

Continuing contact with the people that are being helped by the project is key. "Engineering Innovators without Borders" seeks to maintain a hand in hand relationship everywhere the devices are used. In addition, the devices built and piloted will be assessed to determine customer satisfaction and suitability for use in the developing world ${ }^{12}$.

Another outlet of the design comes from Gambia. A need for a human powered grain crusher was discovered by a recent "Engineers without Borders" trip to Gambia. Currently, the design has been sent to Gambia. As a result, feedback will be received from the field and the design can be further improved.

Another major goal is to well publicize this project. Aspects of this include making sure the "Engineering Innovators without Borders" website is updated, creating a brochure for the device once it is completed, and contacting people who could use the device. On the business side of the project, contacting companies and agencies that could provide funding is very important to the continuation of this project.

"Engineering Innovators without Borders" will not stop at the grain crusher. While visiting India, ideas were generated in a meeting with the National Innovation Foundation (NIF). They have generated many appropriate technologies for India, and work with and DHAN foundation 
to promote their devices. They have developed many devices, from a bicycle that can float and pedal through water, to a smokeless oven.

The NIF gave ideas for new devices, including a peanut shell remover, a coconut tree climber that is safe and can work on trees that are not straight, a soil tiller that does not involve backbreaking effort, and a rice paddy harvester. All of these are possibilities for the future, but the coconut tree climber has been the most invested so far.

\section{Conclusion}

The "Engineering Innovators without Borders" project has come a long way and now that the first project is close to complete, new devices will be developed. With proper funding and motivated students, this project should reach new heights. With the list of contacts in the developing world expanding and the interest in the project growing, more knowledge will be harvested and more devices will be created. 
International Journal for Service Learning in Engineering Vol. 4, No. 1, pp. 48-61, Fall 2009

ISSN 1555-9033

\section{References}

${ }^{1}$ Dhan Foundation website, http://www.dhan.org, Accessed March 21, 2008.

${ }^{2}$ Dewey, J. Experience and Education, NY, Collier, 1938

${ }^{3}$ Weil, S. and McGill, I. A Framework for Making Sense of Experiential Learning In S. Weil and I. Mc Gill (Ed.) Making sense of Experiential Learning (pp. 3-24). Guildford, England: Society for Research Into Higher Education and Open UP, 1989

${ }^{4}$ Westheimer, J., Kahne, J. and Gerstein A. School Reform for the Nineties: Opportunities and Obstacles for Experiential Educators, The Journal of Experiential Education Vol. 15, No. 2, (1992), pp. 44-49.

${ }^{5}$ Beena Sukumaran, Kauser Jahan, Dianne Dorland, Jess Everett, Jennifer Kadlowec, Zenaida Gephardt, and Steven Chin, "Engineering Clinics: An integration of research into the undergraduate engineering curriculum," CUR quarterly, Vol. 26, No. 3, (2006), pp. 115-121.

${ }^{6}$ James Newell, Anthony Marchese, Ravi Ramachandran, Beena Sukumaran, Roberta Harvey, "Multi-disciplinary design and communication: a pedagogical vision," International Journal of Engineering Education. Vol. 15 (1999), pp. $376-382$.

${ }^{7}$ Mehta, Y., and Sukumaran, B. (2007), “Integrating Service Learning in Engineering Clinics," International Journal for Service learning in Engineering, Vol. 2, No. 1,(2007), pp. 32-43.

${ }^{8}$ Saravacos, George D.and Kostaropoulos, A. E. Handbook of Food Processing Equipment. Kluwer Academic/Plenum, 2002.

${ }^{9}$ Compatible Technologies International, http://www.compatibletechnology.org/, Accessed January 2007.

${ }^{10}$ Engineering Innovators without Borders webpage, http://users.rowan.edu/ bacher60/My\%20Web\%20Sites/Grain $\% 20$ Crusher/EIWB\%20Home.htm

${ }^{11}$ Madurai Mill Stores, http://www.maduraimillstores.com, Accessed January 20, 2009.

${ }^{12}$ George, Camille and Shams, Ashley, "The Challenge of Including Customer Satisfaction Into the Assessment Criteria of Overseas Service-Learning Projects," International Journal for Service Learning in Engineering, Vol. 2, No. 2, (2007), pp. 64-75. 